\title{
Responses of queenright and queenless workers of Apis cerana to 9-keto-2(E)-decenoic acid, a pheromonal constituent of the mandibular gland
}

Ken Tan • Zheng-Wei Wang • Hua Li • Ming-Xian Yang • Christian W. W. Pirk • H. Randall Hepburn • Sarah E. Radloff*

K. Tan

Xishuangbanna Tropical Botanical Garden, Chinese Academy of Science, Kunming, Yunnan Province, 650223, People's Republic of China

K. Tan • Z-W. Wang • Hua Li • M-X. Yang • H. R. Hepburn

Eastern Bee Research Institute of Yunnan, Agricultural University, Heilongtan, Kunming, Yunnan Province, People's Republic of China

M-X. Yang • H. R. Hepburn

Department of Zoology and Entomology, Rhodes University, Grahamstown 6140, Republic of South Africa

C. W. W. Pirk

Social Insect Research Group, Department of Zoology and Entomology, University of Pretoria, Pretoria 0002, South Africa

*S. E. Radloff

Department of Statistics, Rhodes University, Grahamstown 6140, Republic of South Africa e-mail: s.radloff@ru.ac.za

Tel: +27 46 6038346; Fax: +27466222723

Abstract In dequeened honeybee colonies ovarian activation occurs in some workers, and the pheromonal bouquets of these laying workers become more queen-like. In the Asiatic honeybee, Apis cerana, we compared the amounts of 9-keto-2(E)-decenoic acid (9-ODA), a mandibular gland pheromone component, between non-laying workers from queenright colonies and laying workers from queenless colonies and, further, applied synthetic 9-ODA to workers to determine whether workers discriminate workers with activated ovaries based on the level of this compound. Levels of 9-ODA were higher in laying workers from dequeened colonies than in non-laying workers from queenright colonies. In both queenright and queenless colonies, more workers treated with 9-ODA were attacked by other workers than were control-treated workers. These results suggest that detection of pseudoqueens in A. cerana is mediated by changes in 9-ODA. 
Key Words: Aggression · Asiatic honeybee $\cdot$ Laying workers $\cdot 9$-keto-2(E)-decenoic acid $\cdot 9-O D A$

\section{Introduction}

The mandibular gland pheromone of a queen honeybee, Apis mellifera L. contributes to the suppression of ovarian activation in workers (Hoover et al. 2003). In queenless colonies, some laying workers develop a pheromonal bouquet, similar to that of queens (Crewe and Velthuis 1980), which stimulates physiological responses in other workers similar to those evoked by queens (Velthuis et al. 1990). In the Cape honeybee, A. m. capensis, the increased level of the queenlike mandibular pheromone substance, 9-oxo-2-(E)-decenoic acid (9-ODA), in workers is correlated with an increase in ovarian activation (Hepburn 1992). High levels of 9-ODA elicit increases in aggressive attacks (Pettis et al. 1995), as well as inhibit ovarian activation in workers (Hillesheim et al. 1989). Also working against reproductive development of workers in colonies (both queenright and queenless) is that other workers can recognize nestmates with activated ovaries (Visscher and Dukas 1995).

Ovarian activation in workers also occurs in queenright colonies of the Asiatic honeybee, Apis cerana Fabricius, and at higher levels in queenless colonies (Sakagami and Akahira 1958). However, it is not known whether A. cerana workers can distinguish workers with developed ovaries. In this study, we measured the 9-ODA content of normal and laying workers, and tested whether 9-ODA elicits attacks against laying workers.

\section{Methods and Materials}

\section{Measurement of 9-ODA content of mandibular pheromone}

Bees were sampled randomly until six workers showing no ovarian activation on dissection were obtained from each colony. After this, all queens were removed from 
the colonies, and two weeks later workers bees were sampled again until six workers showed fully developed ovaries. The heads of these bees were placed in $200 \mu \mathrm{l}$ dichloromethane in GC bottles for two months at $-15^{\circ} \mathrm{C}$.

The extracts were evaporated to dryness under nitrogen and the residues re-dissolved in $20 \mu \mathrm{l}$ of an internal standard, octanoic acid and tetradecane in dichloromethane, and $20 \mu \mathrm{l}$ of bis-trimethylsilyltrifluoroacetamide. Extracts were injected splitlessly into a Hewlett Packard 6890 gas chromatograph, equipped with a 25 x $0.32 \mathrm{~mm}$ i.d., methyl silicone column, programmed from $60^{\circ} \mathrm{C}$ (held for $1 \mathrm{~min}$.) to $110^{\circ} \mathrm{C}$ at $50^{\circ} \mathrm{C} \cdot \mathrm{min}^{-1}$, then to $220^{\circ} \mathrm{C}$ at $3^{\circ} \mathrm{C} \cdot \mathrm{min}^{-1}$. Helium, at $1 \mathrm{ml} \cdot \mathrm{min}^{-1}$ was the carrier gas. The compound 9-ODA was identified, based on comparison of retention time with that of an authentic standard, and quantified in relation to the internal standards.

\section{Observation of workers' responses to 9-ODA}

Experiments were conducted at Yunnan Agricultural University, Kunming, China. Twenty worker bees from each of three queenright and queenless colonies of Apis cerana were anesthetized with $\mathrm{CO}_{2}$ and marked. They were divided into equal groups: one treated with $10 \mu \mathrm{g} 1 \% \mathrm{w} / \mathrm{w}$ 9-ODA, similar to the quantity produced by a laying worker, another with $10 \mu \mathrm{g} 200 \% \mathrm{w} / \mathrm{w}$ 9-ODA, similar to that produced by a queen (Tan et al. 2009), and the third (control) treated with $10 \mu \mathrm{g}$ distilled water. When the anesthetized workers recovered, they were returned to their hives on a single frame and monitored for 3 min with digital video cameras, one on each side of the frame, to record any aggressive behaviour.

Statistical Analyses Independent $t$-tests compared the amounts of 9-ODA between queenright $A$. cerana workers and queenless laying workers. Chi-square tests were used to compare the aggression behaviour, directed to treated workers, between test and control groups, and between queenright and dequeened colonies. Count data were used in the chi-square calculations. 


\section{Results}

Mean 9-ODA content in extracts of $A$. cerana workers was significantly different $\left(t_{4}=4.8, P<0.009\right)$ between queenright $[0.014 \pm 0.005 \mu \mathrm{g}(\mathrm{SD})]$ and queenless $[0.096 \mu \mathrm{g}$ \pm 0.029 (SD)] colonies. In queenright colonies, within 3 min. after workers treated with 9-ODA (either $0.1 \mu \mathrm{g}$ or $0.2 \mathrm{mg} /$ bee) were released, greater percentages $(0.1 \mu \mathrm{g}$ : $\left.\chi^{2}{ }_{1}=25.5, P<0.001 ; 0.2 \mathrm{mg}: \chi_{1}^{2}=38.6, P<0.001\right)$ of treated workers were attacked compared to the control groups (Table 1). In queenless colonies, greater percentages (0.1 $\left.\mu \mathrm{g}: \chi_{1}{ }_{1}=18.3, P<0.001 ; 0.2 \mathrm{mg}: \chi_{1}^{2}=21.8, P<0.001\right)$ of treated workers were also attacked after release, compared to the control groups (Table 1). However, overall, there were fewer attacks against treated workers in queenless colonies than in queenright colonies. This effect was significant for treatment with $0.2 \mathrm{mg}$ of 9-ODA $\left(\chi_{1}^{2}=12.3\right.$, $P=0.001)$, but not quite significant for treatment with $0.1 \mu \mathrm{g}\left(\chi_{1}^{2}=3.4, P=0.067\right)$. In both queenright and queenless colonies, workers were more sensitive to the higher dose of 9-ODA. The difference was significant for the queenright colonies but not significant for queenless colonies (queenright: $\chi_{1}^{2}=5.5, P=0.019$; queenless: $\chi_{1}^{2}=0.3, P=0.606$ ) (Table 1).

\section{Discussion}

Within a week of being dequeened, some $40 \%$ of workers in an A. cerana colony have activated ovaries (Tan et al. 2009). We found that pheromonal changes corresponded with this ovarian activation, with the mandibular gland extract of a laying worker containing approximately seven times as much 9-ODA as a worker without activated ovaries.

In our behavioral tests, we showed that other workers attacked workers with developed ovaries and a queen-like 9-ODA bouquet. It is likely the detection of these pseudoqueens is mediated by the pheromonal cue (Hepburn 1992). Although laying workers increased their 9-ODA content, it was still considerably less than that produced by queens. In $A$. mellifera, such a difference in mandibular gland content is sufficient 
for laying workers to be perceived as such by their nestmates and be attacked (Plettner et al. 1995).

Interestingly, more workers treated with 9-ODA were attacked in queenright colonies than in queenless ones. This effect may, in part, be due to greater numbers of attacking bees lacking ovarian activation in queenright colonies than in queenless ones (Tan et al. 2009). However, it may also be due to an increased tolerance of laying workers in queenless colonies over that in queenright colonies, perhaps mediated by prior 9-ODA levels in the respective colony types.

Acknowledgements Financial support was granted by the Xishuangbanna Tropical Botanical Garden, Chinese Academy of Science and the National Agricultural Production Systematic Fund (nyncytx-43-kxj13) to Ken Tan. We thank the Institut für Bienenkunde, Oberursel, Germany for the gift of 9-ODA and Professor Crewe, from the University of Pretoria, for the use of GCs.

\section{References}

CREWE, R. M., and VELTHUIS, H. H. W. 1980. False queens: a consequence of mandibular gland signals in worker honeybees. Naturwissenschaften 67:467-469.

HEPBURN, H. R. 1992. Pheromonal and ovarial development co-vary in Cape worker honeybees, Apis mellifera capensis. Naturwissenschaften 79:523-524.

HILLESHEIM, E., KOENIGER, N., and MORITZ, R.F.A. 1989. Colony performance in honeybees (Apis mellifera capensis Esch.) depends on the proportion of subordinate and dominant workers. J. Behav. Ecol. Sociobiol. 24:291-296.

HOOVER, S. E. R., KEELING, C. I., WINSTON, M. L., and SLESSOR, K. N. 2003. The effect of queen pheromones on worker honey bee ovary development. Naturwissenschaften 90:477-480.

PETTIS, J. S., WINSTON, M. L., and SLESSOR, K. N. 1995. Behavior of queen and worker honey bees (Hymenoptera, Apidae) in response to exogenous queen mandibular gland pheromone. Ann. Entomol. Soc. Am. 88:580-588. 
PLETTNER, E., SUTHERLAND, G. R. G., SLESSOR, K. N., and WINSTON, M. L. 1995. Why not be a queen? Regioselectivity in mandibular secretions of honeybee castes. J. Chem. Ecol. 21:1017-1029.

SAKAGAMI, S.F., and AKAHIRA, Y. 1958. Comparison of ovarian size and number of ovarioles between the workers of Japanese and European honeybees (Studies on the Japanese honeybee, Apis indica cerana Fabricius, I). Kontyû 26:103-109.

TAN, K., YANG, M-X., RADLOFF, S. E., PIRK, C. W. W., CREWE, R. M., PHIANCHAROEN, M., HEPBURN, H. R., and OLDROYD, B. P. 2009. Worker reproduction in mixed-species colonies of honey bees. Behav. Ecol. 20:1106-1110.

VELTHUIS, H. H. W., RUTTNER, F., and CREWE, R. M. 1990. Differentiation in reproductive physiology and behaviour during the development of laying worker honeybees, pp. 231-243, in W. ENGELS (ed.). Social Insects. Springer, Berlin. VISSCHER, P. K., and DUKAS, R. 1995. Honey bees recognize development of nestmates' ovaries. Anim. Behav. 49:542-544. 
Table 1 Number of treated Apis cerana workers attacked by nestmates (Mean $\pm \mathrm{SD} \%),(N=10$ workers per colony, 3 colonies)

\begin{tabular}{llllll}
\hline \multirow{2}{*}{ Treatment 9-oxo-2-(E)-decenoic acid amount } & Colony & Queenright & \multicolumn{3}{l}{ Queenless } \\
\cline { 2 - 6 } & & Control & Test & Control & Test \\
\hline $0.1 \mu \mathrm{g}$ & 1 & 0 & 6 & 0 & 4 \\
& 2 & 1 & 6 & 0 & 4 \\
& 3 & 1 & 9 & 0 & 6 \\
$0.2 \mathrm{mg}$ & Total & $2(6.7 \pm 5.8 \%)^{\mathrm{c}}$ & $21(70.0 \pm 17.3 \%)^{\mathrm{a}}$ & $0(0.0 \pm 0.0 \%)^{\mathrm{c}}$ & $14(46.6 \pm 11.5 \%)^{\mathrm{a}}$ \\
& 1 & 1 & 9 & 0 & 5 \\
& 2 & 1 & 9 & 0 & 5 \\
& 3 & 2 & 10 & 0 & 6 \\
\hline
\end{tabular}

${ }^{\mathrm{a}}$ Mean percentages within one column or one row followed by a different letter are significantly different 